WellBeing International

WBI Studies Repository

6-2012

\title{
Wild Justice Redux: What We Know About Social Justice in Animals and Why It Matters
}

\author{
Jessica Pierce \\ University of Colorado \\ Marc Bekoff \\ University of Colorado
}

Follow this and additional works at: https://www.wellbeingintlstudiesrepository.org/acwp_ena

Part of the Animal Studies Commons, Behavior and Ethology Commons, and the Comparative Psychology Commons

\section{Recommended Citation}

Pierce, J., \& Bekoff, M. (2012). Wild justice redux: What we know about social justice in animals and why it matters. Social Justice Research, 25(2), 122-139.

This material is brought to you for free and open access by WellBeing International. It has been accepted for inclusion by an authorized administrator of the WBI Studies Repository. For more information, please contact wbisr-info@wellbeingintl.org.

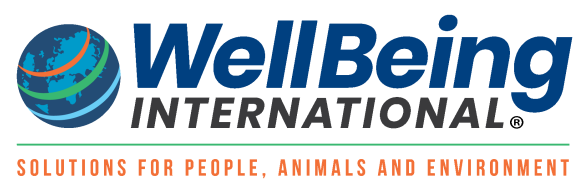




\title{
Wild Justice Redux: What We Know About Social Justice in Animals and Why It Matters
}

Jessica Pierce and Marc Bekoff

University of Colorado

\section{$\underline{\text { KEYWORDS }}$}

social justice, animals, wild justice, play, prosocial, captive, fairness, inequity aversion, ethics, empathy, cooperation, morality, primates, canids, cognitive ethology

\begin{abstract}
$\underline{\text { ABSTRACT }}$
Social justice in animals is beginning to attract interest in a broad range of academic disciplines. Justice is an important area of study because it may help explain social dynamics among individuals living in tightlyknit groups, as well as social interactions among individuals who only occasionally meet. In this paper, we provide an overview of what is currently known about social justice in animals and offer an agenda for further research. We provide working definitions of key terms, outline some central research questions, and explore some of the challenges of studying social justice in animals, as well as the promise of the work we're proposing. Finally, we suggest why continued research into animal cognition and social behavior has significant ethical implications for our treatment of nonhuman animals.
\end{abstract}

In our 2009 book Wild Justice, we argued that animals have the capacity for moral behavior, and not merely the early traces of what was to evolve into morality in humans but full-fledged moral behaviors in their own right. We defined morality as "a suite of interrelated other-regarding behaviors that cultivate and regulate complex interactions within social groups." For the sake of discussion, we divided moral behavior into three "clusters" or general groupings of behavior: altruistic and cooperative behaviors, empathic behaviors, and justice behaviors. Of these, justice is probably the most cognitively complex and also the least broadly distributed across different taxa.

We were able to gather extensive data on the altruism/cooperation cluster and had sufficient research to make a strong case for the empathy cluster. Yet we had a harder time supporting our hypothesis that animals engage in behaviors falling within the justice cluster. The literature was slim, and with the exception of fairness in the context of play behavior, particularly among canids (members of the dog family), little research had been conducted on social justice in animals. There were a few scattered studies on inequity aversion in non-human primates (Brosnan \& de Waal, 2003), one study on dogs (Range et al., 2008), suggestive work on corvids (Heinrich, 1999). But that was pretty much it. Indeed, it seemed unclear whether, and to what extent, animals are capable of behavior that can properly be called justice.

Social justice in animals is now beginning to attract broad interest (e.g., Peterson, 2011; Brosnan, 2006; see also Price \& Brosnan, 2012, this issue; Range, Leitner, \& Virányi, 2012; Horowitz, 2012, this issue; 
Raihani \& McAuliffe, 2012, this issue; Bräuer \& Hanus, 2012, next issue; Yamamoto \& Takimoto, 2012, next issue). Biologists, ethologists, psychologists, anthropologists, philosophers, and other researchers from a wide range of academic disciplines have set to work trying to tease out how to study the phenomenon of social justice in animals.

This special issue of Social Justice Research represents an important effort to pull together what we currently know about social justice in animals. Justice is an important area of study because it may help explain social dynamics among individuals living in tightly-knit groups, as well as social interactions among individuals who only occasionally meet. Consolidating this research is an invaluable step for it will help us figure out what we know, what we don't know but need to know, and also will help give a sense of where research might head in the future.

\section{What Do We Know About Social Justice in Animals?}

\section{Putting Justice in Perspective: How and Why Animals Get Along}

Within evolutionary biology, one of the central puzzles of the past several decades has been trying to understand why animals work together and get along. Why, in a world of competition and bloody struggle to win at all costs, would animals undertake to help one another or be friendly? Why would they engage in what biologists call "prosocial" behavior? Consider, for example, the surprising results of research conducted by Washington University anthropologist Robert Sussman and his colleagues. After collecting and analyzing data on the social interactions of various primate species, the researchers came to the conclusion that the vast majority of social interactions were affiliative rather than agonistic. Grooming and playing were far more common than fighting (Sussman, Garber, \& Cheverud, 2005). In his 2011 book, with Robert Cloninger, Sussman provides strong evidence that this is true among animal species in general, not just primates (Sussman \& Cloninger, 2011).

Sussman's work is indicative of a significant paradigm shift occurring within evolutionary biology. No longer is competition the only or even the guiding metaphor for evolution. More and more biologists recognize the importance of cooperation and positive social interactions, not just among humans but as a broad evolutionary strategy. And prosociality is now seen not just as a by-product of competition, but as a central driving force of evolution in its own right. Biologists are also increasingly interested in group selection as a central component in the evolution of sociality. The literature of evolutionary biology is more and more speckled with the language of sociality: cooperation, fairness, reciprocity, empathy, trust, consolation, altruism. A blossoming interest in justice is part of this larger trend.

And it makes perfect sense, too, that prosocial behavior could be a central driver of evolution. Given that life in the wild can be perilous and getting injured can have dire consequences, we would expect to see patterns of prosocial behavior evolve in diverse species. In animal societies it is essential that there be mechanisms for avoiding conflict, as well as ways of resolving conflict that don't involve fighting, given the potential costs of injurious encounters. Even an animal who "wins" a fight will sometimes sustain injuries that will compromise his or her fitness, and fighting takes time and energy. Across diverse species we see the evolution of highly ritualized threat displays and submission and appeasement behavior that decrease the likelihood of conflict.

Prosocial behavior not only helps animals avoid injury. By working together, individuals comprising a group can accomplish much more than they could alone, as for example in cooperative hunting, vigilance, and care of the young. Peter Corning, in The Fair Society, notes that social relationships, and especially social networks, can have real value and add productivity to any purposeful activity. Social capital provides the wherewithal to achieve individual goals in contexts where we can benefit from cooperating 
with others (Corning, 2011, p. 82). Thus the essential first principle in every social relationship, and in every (stable) human society, is honesty and fair play. Deception, lying, cheating, stealing, or any other action that deliberately causes harm is unfair conduct, and "undermines the implicit social contract based on mutual trust and reciprocity that we ultimately all depend on in our social relationships" (Corning, 2011, p. 17).

What is Justice?

A whole range of behaviors grease the wheels of sociality. So, exactly which types of prosocial behaviors could be considered "justice" behaviors? As scientists' are increasingly interested in justice or fairness behaviors in animals, it is important to clarify what, precisely, we are looking for. Unfortunately, because the study of justice in animals is so new, researchers don't yet have a clear definitional landscape within which to work.

Even after several millennia philosophers disagree about the meaning and content of "justice." At a most general level, "justice" refers to what is merited or deserved. Distinctions are drawn between commutative, retributive, restorative and distributive justice and between equality (equal distribution) and equity (distribution by merit or deservingness). Distributive justice, the area of greatest interest to philosophers, relates to what goods need to be distributed, between who or what, and based on what considerations. Justice has in recent years become strongly associated with fairness, and the two terms are often used synonymously, a testament to the influence of political philosopher John Rawls (1971). But it is important to note that this is a modern (and a philosophically narrow) iteration of justice. Historically, justice has also been understood as harmony, balance, or equilibrium.

Justice has only recently been used within the context of biology and so the meaning and application of the concept is still very much open to debate. As we study social justice in animals and as we work to clarify the vocabulary we should be comfortable with some level of ambiguity. At the same time and precisely because of the ambiguity, individual researchers should be very clear about how they are using terms. There are many nuances to be worked out, but we would propose the following distinctions, as a place to begin discussion. (We might be wrong about each of these.)

In Wild Justice we proposed justice behaviors as one of three major clusters of moral behavior in animals. Justice, in other words, is an umbrella term covering a range of behaviors related to expectations about what one deserves and how one ought to be treated in relationships with others. The biological function of these behaviors is to encourage and sustain fitness-enhancing systems of cooperation. Fairness is one specific type of justice behavior, related to how costs and benefits are distributed. A sense of fairness includes attention to equity (how much an individual deserves) and equality (everyone deserves the same). Other behaviors that might be important components of or overlap with justice include reciprocity, collaboration, punishment, reconciliation, spite, fair play, sharing, retribution, and forgiveness. The justice cluster also covers emotional reactions to injustice (anger, indignation) and to justice (pleasure, gratitude, trust).

It is important to stress that justice is not synonymous with morality: some justice behaviors can properly be called moral but not all. At the same time, some moral behavior might not be fair. Justice is also not equivalent to fairness and the terms should not be used interchangeably. Fairness represents a specific type(s) of justice behavior. Justice behaviors are intimately interconnected with behaviors in the other two clusters, namely altruism/cooperation and empathy, but the relationships still remain to be ironed out. This is a work in progress that may in fact never be solved to everyone's agreement. 
We recognize that our conceptualization of social justice is uncomfortably broad. Indeed, both reviewers of this paper were uneasy with our use of justice as an umbrella term, and urged us to offer a narrower definition. However, we believe that narrowing our working definitions at this point is premature, and that a broad definition will do more to encourage comparative research across a diverse array of animal species who exhibit varying degrees of sociality. ${ }^{1} \mathrm{~A}$ more refined understanding (and definition) of justice in animals must be allowed to develop alongside and out of the blossoming body of research. As one of our reviewers said, "The crux is to identify an account of justice with just the right amount of breadth." This is absolutely correct. The reviewer went on to say, "I wish I knew how to do that." So do we. ${ }^{2}$

\section{What Do We Actually Know About Justice in Animals?}

As we said, there are far fewer data on social justice in animals than there are on many other aspects of cooperative and prosocial behavior. Nevertheless, there are scattered studies of a few species that offer tantalizing suggestions of justice behaviors in non-human animals.

The literature on prosocial behavior in primates is well-established and clearly shows that primates engage in reciprocity (including tit-for-tat exchange of favors, grooming, food-sharing), consolation behavior, conflict resolution, coalition building, retribution and punishments for cheaters or free-loaders. Several primate studies have focused attention on "inequity aversion," a negative reaction arising when expectations about fair distribution of resources have been violated. In particular, researchers have begun to explore a particular form of inequity aversion in which an animal reacts negatively when other animal receives more of something desirable.

In one of the most well-known studies, Sarah Brosnan and Frans de Waal trained a group of captive capuchin monkeys to use small rocks as tokens of exchange for food. Pairs of females were then asked to barter for treats. One monkey was asked to swap a rock for a grape; after watching this exchange, a second animal was asked to exchange their rock, for which she was given a piece of cucumber, rather than the much more desirable grape. The short-changed monkeys seemed to become indignant and often refused to cooperate further and sometimes even hurled the offending cucumber at the researcher (Brosnan \& de Waal, 2003). In a later study, van Wolkenten, Brosnan, and de Waal confirmed these results with a larger pool of capuchin subjects, and further explored the role of effort in generating inequity responses. They found that capuchins were, indeed, sensitive to the level of effort expended to earn a reward (van Wolkenten, Brosnan, \& de Waal, 2007).

A study by Brosnan, Schiff, and de Waal (2004) used a similar experimental setup to explore inequity aversion in chimpanzees and found negative reactions to inequity in reward. This study went a bit further and added some nuance: although the chimpanzees responded to discrepancies in reward, they seemed indifferent to discrepancies in level of effort. The strength of the chimpanzees' reactions to inequity varied according to social context, including group size and relatedness. Interestingly, levels of tolerance for inequity were higher in groups with longstanding and closely knit relationships. A 2010 study by Brosnan and colleagues further elucidated the conditions under which chimpanzees responded to inequity, exploring for example the interactions between individual expectations (based on an animal's own previous experience) and social expectations (based on watching what a partner receives) (Brosnan, Talbot, Ahlgren, Lambeth, \& Shapiro, 2010).

Since then, several studies have sought to further refine our understanding of inequity aversion. Brosnan and colleagues published results of an investigation into what happens when capuchins are faced with a trade-off between equity and prosociality (Brosnan et al., 2010). A study by Neiworth, Johnson, Whillock, Greenberg, and Brown (2009) tested for a sense of inequity in cotton top tamarins, and found that this species of New World monkey does assess social inequity, but only under conditions of limited resources 
and a requirement of work (Neiworth et al., 2009). Talbot and colleagues explored the link between cooperative behavior and inequity aversion by looking at the behavior of squirrel monkeys, a species which does not cooperate extensively (Talbot, Freeman, Williams, \& Brosnan, 2011; see also Price \& Brosnan, 2012, this issue; Bräuer \& Hanus, 2012, next issue; Yamamoto \& Takimoto, 2012, next issue).

Inequity aversion has also been studied in the domestic dog. Friederike Range's research, published in 2009, sought to expand the scope of inequity aversion research beyond primates. She investigated whether dogs show sensitivity to inequity in reward. The dogs did, indeed, show a tendency to refuse to cooperate if they observed a partner receiving a reward for the same work, while they got nothing. But unlike primates, the dogs did not seem to react to differences in quality of reward (Range, Horn, Viranyi, \& Huber, 2008; see also Range et al., 2012, this issue; Horowitz, 2012, this issue).

We have one other very important line of research into social justice behavior within social canids. Work done by one of us (Bekoff, 1995; summarized in Bekoff \& Pierce, 2009) on social play behavior in infant domestic dogs and their wild relatives, coyotes and gray wolves suggests that a sense of fairness is crucial to negotiating playful interactions. When canids play, they use actions like biting, mounting, and body-slamming one another, which are also used in other contexts, like fighting or mating. Because those actions can be easily misinterpreted, it's important for animals to clearly state what they want and what they expect.

Animals engage in two activities that help create an equal and fair playing field: self-handicapping and role-reversing. Self-handicapping (or "play inhibition") occurs when individuals perform behavior patterns that might compromise them outside of play. For example, coyotes will inhibit the intensity of their bites, thus abiding by the rules and helping to maintain the play mood. Role-reversing happens when a dominant animal performs an action during play that wouldn't normally occur during real aggression. For example, a dominant wolf wouldn't roll over on his back during fighting, making himself more vulnerable to attack, but would do so while playing.

When play gets too rough, canids keep things under control by using bows to apologize. For example, a bow might communicate something like, "Sorry I bit you so hard-I didn't mean it, so let's continue playing." For play to continue, it's important for individuals to forgive the animal who violated the rules. The social dynamics of play require that players agree to play and not to eat one another or fight or try to mate. When there's a violation of those expectations, others react to the lack of fairness. For example, young coyotes and wolves react negatively to unfair play by ending the encounter or avoiding those who ask them to play and then don't follow the rules. Research shows that animals who violate the trust of their playmates are often ostracized; violation of the rules of play is maladaptive and can disrupt the efficient functioning of the group. For example, among dogs, coyotes, and wolves, individuals who don't play fairly find that their invitations to play are ignored or that they're simply avoided by other group members. Marc's long-term field research on coyotes living in the Grand Teton National Park, near Jackson, Wyo., shows that coyotes who don't play fairly often leave their pack because they don't form strong social bonds. Such loners suffer higher mortality than those who remain with others.

Finally, and moving even more dramatically away from primates, is research suggesting that justice behaviors might also be found among corvids. Raven expert Bernd Heinrich has observed that ravens remember an individual who consistently raids their caches, if they catch him in the act. Sometimes, though, an individual will join an attack on an intruder, even if he or she did not directly observe the thief in action. Heinrich writes, "It was a moral raven seeking the human equivalent of justice, because it defended the group's interest at a potential cost to itself" (Heinrich, 1999, p. 282). Corvids will likely be a rich area for further exploration. 


\section{Where Do We Go from Here? Learning More About Social Justice in Animals}

In this section, we'll talk about some of the challenges of studying social justice in animals, as well as the promise of this work. We'll discuss vocabulary, method, human-animal comparisons, and ethics.

How Should We Talk About Social Justice in Animals?

One thorny set of research questions involves what language to use when studying, describing, interpreting, and explaining animal behavior. When we study social justice or other seemingly moral behaviors in animals the definitional questions take on several added layers of complexity because the language of morality is controversial and imprecise to begin with, and doubly so when used in studies of animal behavior. Definitional questions are conceptual and philosophical, as well as scientific, and as such will likely elude definitive resolution and universal agreement among those interested in social justice.

One of the central questions needing to be addressed is whether the same language should be used to describe animal moral behaviors that we employ in talking about human moral behaviors. Using the same language is certainly the most scientifically parsimonious approach, suggesting evolutionary continuity in moral behaviors, including behaviors related to justice, among various taxa. But it is a little more complicated than this, because the language of morality and justice and fairness did not arise within the context of science, and surely not within studies of animal behavior, and the application of moral language to animals is quite new. Nor has the vocabulary of social justice been established within scientific disciplines.

Do we, instead, need some way to differentiate animal behavior from human behavior? Should we, for example, distinguish between justice ${ }_{\mathrm{h}}$ (human justice) and justice $\mathrm{a}_{\mathrm{a}}$ (animal justice) or justice (biological $_{\mathrm{b}}$ fairness)? Fairness ${ }_{h}$ and fairness ${ }_{a}$ (see for example Ayala, 2010)? Or perhaps even coin new terms for describing animal behavior ("animequity")?

One of the strongest arguments against a shared vocabulary and in favor of new language is that a shared vocabulary encourages anthropomorphism (attributing human qualities to non-human animals, as in "my dog felt so guilty for chewing my shoe!"), and some worry that anthropomorphic language may too strongly color the way we study and interpret animal behavior (Horowitz \& Bekoff, 2007; see also Horowitz, 2012, this issue). By using "justice" to describe what we are looking for in animals we may (perhaps even subconsciously) look for human-like behaviors, and fail to see or understand the uniqueness of a given behavior in a certain species of animal. We may be inclined to look at a certain species and declare them incapable of justice, simply because they do not fit our human (or primate) expectations.

Using the same terms in different disciplinary contexts can also be confusing. A perfect case in point is "altruism," which has a different meaning within biology and other scientific disciplines than it does within philosophy and other humanistic fields. Although scientists and philosophers may understand the distinction, the lay public likely will not, and it is essential that new insights into animals be made accessible to a wide audience. In using a term like "justice," which has strong resonance with the public, there is the danger of lay public misunderstanding as has happened with "selfish" in relation to Richard Dawkins' talk about selfish genes (Dawkins, 1976).

A final argument against shared vocabulary is the sheer complexity and ambiguity of moral language, particularly the term "justice," even within its home discipline of philosophy. Why adopt one of the most complex and controversial words in philosophy and then proceed to make it even more complicated? 
Despite these difficulties, we believe a shared vocabulary is preferable to one that seeks a sharp distinction between human justice and justice in other animal species, and which thus violates the principle of evolutionary continuity among animals. Charles Darwin argued that differences among species are difference in degree rather than kind. Thus, if we have something, other animals likely do too. The most parsimonious (and compelling) explanation for moral behaviors in animals is a Darwinian one, namely that moral behaviors are an evolutionary adaptation to group living and have arisen across a broad range of species. Morality is not unique to humans. And if we are talking about the same phenomenon we ought to use the same language.

A shared vocabulary is what we already have in relation to animal justice and what seems to have arisen naturally in the course of cross-disciplinary research. The developing science of justice is a diverse effort involving, at the minimum, animal behavior, evolutionary biology, neurobiology, ethology, behavioral genetics, philosophy, theology, sociology, anthropology, and psychology. It is very hard to talk across disciplines when concepts have different, perhaps even contradictory, meanings within different disciplines. Even if we can't ultimately agree on a single definition, the collaboration will force all researchers to be more precise with their language.

How Can We Best Study Social Justice in Animals?

Because researchers from different disciplines and with different backgrounds are interested in questions about morality and justice, we not only have to agree about terminology but also about the methods used to collect data relevant to the questions at hand (Lehner, 1996). Inquiries into social justice in animals are indeed challenging and often frustrating and it is important to be as rigorous as possible when studying questions that center on this social phenomenon.

\section{Wild or Captive?}

One of the primary methodological tasks in the study of animal social justice behavior, and more broadly in any study of animal cognition (human or nonhuman), is to discover precisely what cognitive mechanism or mechanisms underlie a particular observed behavior. This, of course, is easier said than done.

Because of the immense complexity involved in trying to understand animal behavior, a common approach is to study captive populations in a controlled, captive environment. This way, researchers can exert some control over experimental conditions, and can reduce the opportunity for confounding factors to enter the picture. And these controlled, captive studies are exceedingly important and have provided most of the raw data we now have about social justice behaviors in animals. Nevertheless, laboratory studies of animal cognition are fraught with problems.

Perhaps the most significant challenge is that animals in captivity do not necessarily behave just like their wild relatives, so it is very hard to generalize from the behavior of individuals in a captive group to members of the same species living in the wild. As a case it point, it is well known that the behavior of captive octopi does not resemble the behavior of their wild relatives (Bekoff, 2010; Montgomery, 2011). A particular issue related to studying social justice-and one which is at play in the studies of inequity aversion in chimpanzees mentioned above-is that researchers will ask animals to perform a cognitive task that is unlike anything they would encounter in their natural environment, such as pulling levers, exchanging tokens for cucumbers and grapes, or playing an ultimatum game. Sometimes, animals given a novel task will reveal cognitive skills not observed in the wild. For example, although gorillas in the wild have not been observed to use tools, the animals can become adept tool-users in a laboratory setting (Tomasello \& Call, 2011). Conversely, captive studies can lead us to conclude that capacities or behaviors do not exist, where perhaps they do. For example, it has been difficult to demonstrate that non- 
human animals have a theory of mind in captivity but this does not provide evidence that wild relatives do not. More to the point, just because we may fail to observe social justice behaviors in captive setting does not mean and should not be taken as evidence that wild members of the same species do not use justice in their social interactions.

Furthermore, studies using captive populations are often quite small, sometimes consisting of only a handful of animals. Not only does a very small study population affect the reliability of data, but social relationships and networks are likely different than they would be in a larger group; thus social interactions and behaviors may, by their nature, be particularly hard to study. Results obtained from one captive group cannot necessarily be reliably generalized to other captive groups much less to wild relatives. And some species are much more abundant and available for captive study than others, thus leading to a narrow research focus.

Research on cognitive ethology, including the study of social justice, must have a strong footing in what animals do in the wild when they are living in natural groups and are able to perform their full repertoire of behavior. We can use captive data as a guide to what to look for in the wild, but the use of field studies in vitally important. Unfortunately, field studies that shed light on social justice are extremely rare.

Studies in the field are not without their own challenges. Some difficulties are geographical (the animals live in dangerous or hard to reach places; a group of animals may cover a vast territory), some are practical (field studies can be very expensive, can require a long span of time to get accurate data, involving years of observation, not weeks or days, as in the lab, and are often hard to get funded). And of course some of the difficulties are scientific: it is exceedingly difficult to control or even recognize the variables that may be influencing behavior, particularly the past experiences of each individual animal. Even being able to identify each unique individual in a wild group_an essential prerequisite to studying their behavior-can take a highly skilled, well-practiced, and very patient researcher considerable time and effort.

Michael Tomasello and Josep Call (2011) proposed one solution to the various methodological challenges of studying primate cognition, both in the field and in the lab (and this would apply equally to non-primate studies). They recommend the creation of large data banks which could house primary data and videotapes; this would, they argue, facilitate the replication and cross-examination of data and would encourage the pooling of data across diverse disciplines (Tomasello \& Call, 2011). Something like this would be very useful in relation to the study of social justice.

Captive studies are likely to be the main source of data on social justice, at least in the near term. But various cautions are in order. Because justice is a social phenomenon we need to be sure that the animals under study are able to behave as card-carrying members of their species, and the captive conditions under which they are kept and the methods used do not compromise either the actions individuals are able to perform or significantly alter the formation or functioning of social groups. (Bekoff \& Pierce, 2009; Bekoff, 2010; and below). We also must be careful to keep the well-being of the animals at the forefront of our attention, not only because ethics demands such but also because research can be skewed if animals are unhealthy or unhappy. We know, for example, that the behavior of stressed animals is not necessarily typical species behavior (Bekoff, 2010).

\section{Subjects of Study}

Most of the research on moral behavior in general, and on social justice in particular, has been conducted on other primates, but the focus needs to shift. This is not to say that primates aren't interesting subjects of study - they are. And research on primate behavior has, and will continue to be, very fruitful in this 
area. But it must not remain the only or even central focus of attention when it comes to social justice. We need to expand the range of species under consideration, perhaps even to include non-mammalian species such as fish (see Raihani \& McAuliffe, 2012, this issue). And we need to willingly suspend our presuppositions, stereotypes, and prejudices about which animals have complex and interesting social behavior, moving beyond our obsession with the so-called "cognitive elite". This special issue represents an important step in that direction.

The spurious tendency to link human behavior with other "higher" species, particularly a few specific nonhuman primate species, will do more to stymie research than further it, and we must always be on guard against this all-too-easy mistake. To take just one example, Keith Jensen and colleagues published a very interesting study in 2007 on fairness (or lack thereof) in chimpanzees. Jensen's team set up an ultimatum game, a well-known model of economic decision-making among humans, in which individuals can either accept or reject proposed divisions of a monetary windfall. In this case, the "money" was raisins, and chimpanzees were tested to see whether they would accept unfair offers (they did) and whether they would make unfair offers (they did). Jensen and his colleagues discovered that chimpanzees don't play the game like humans typically do. From this, they concluded that "otherregarding preferences and an aversion to inequitable outcomes, which play key roles in human social organization, distinguish us from our closest relatives" (Jensen, Call, \& Tomasllo, 2007, p. 107). In other words-and as a headline in the Los Angeles Times declared-because chimpanzees don't seem interested in fairness during an ultimatum game, fairness is only human. They also concluded that if the closest relative to humans, Pan troglodytes, doesn't have a sense of fairness, no other animal will either. Yet all we have really learned from Jensen's study is that a group of eleven captive chimpanzees don't behave like humans subjects in a contrived ultimatum game. The research itself is interesting, but the spin put on it by Jensen and by the media was perhaps counterproductive.

The quest to understand the evolution of social behavior will require us to cast a much broader net, and to explore a diverse range of social behaviors and types of social organization. And if we are trying to understand the evolution of human social behavior, in particular, we may need to look beyond our closest genetic relatives, even though this might seem counter intuitive. Nobel laureate Niko Tinbergen (1972) and renowned conservation biologist George Schaller along with award-winning anthropologist Gordon Lowther (1969) have suggested that social carnivores, even though more phylogentically distant from early hominids than nonhuman primates, are ecologically similar in important ways. Patterns of social behavior and organization among wolves, hyenas, wild dogs, and lions-group dynamics, dominance hierarchies, land tenure systems, cooperative hunting techniques, food-sharing, and the division of labor-resemble those of early hominids in a number of ways (see also Thompson, 1975).

\section{Privacy of Mind, Subjective States, and Parsimony}

Many people are skeptical of research that delves into the minds of other animals because of the supposed inaccessibility of what is happening in their heads. While we can never know precisely what other animals (and likely other humans) are thinking and feeling we can collect data that allow us to make very accurate predictions of their behavior when we infer certain subjective states of mind based on their outward behavior (Allen \& Bekoff, 1997; Bekoff, 2007). Interminable arguments over whether we can really know what another animal is thinking or feeling are tiresome and get us nowhere and surely will not encourage the research that needs to be done in this and other fields (Bekoff, 2006).

In offering explanations of animal behavior some people like to appeal to the notion of parsimony: we should always give the simplest possible explanation of observed behavior. They argue that mechanistic or reductionist explanations are simpler than cognitive explanations that appeal to mental states, but this is not necessarily the case (Allen \& Bekoff, 1997; Bekoff, 1996). Often stimulus-response explanations 
are quite tedious and are more convoluted than explanations that appeal to subjective states. Darwin's ideas about evolutionary continuity provide a strong basis for arguing that non-human animals are capable of expressing social justice. For animals living in complex social groups in which it is conceivable or probable that moral behavior and social justice have evolved it could be quite parsimonious to say they are following rules of right and wrong or acting fairly or unfairly (Bekoff \& Pierce, 2009).

\section{Human-Animal Comparisons: Dangers and Opportunities}

There is great interest in the origins of human moral behavior, and research into animal behavior most certainly contributes to our understanding of how we came to be as we are (see Olson, 2012, next issue; Skitka, 2012, next issue; Chen \& Houser, 2012, next issue; Christen \& Glock, 2012, next issue). But caution is in order, because many books and articles ostensibly about "origins" do not really deal with evolutionary origins because, for one, they only deal with a narrow array of animals. And in some ways "origins" is a misleading metaphor for what we're after. An "origin" is an original source, a fountainhead. Human moral behavior has evolved alongside, not out of, moral behaviors in other species. Research on the social behavior of animals clearly dovetails with the quest to understand human morality, but our main agenda is trying to understand animals themselves.

That said, it is interesting, perhaps even inevitable, to make comparisons between animals and humans. But comparative work needs to proceed with caution. A very common mistake is to approach animal morality using this simple recipe: human morality is defined by $\mathrm{X}$; animals aren't capable of $\mathrm{X}$; therefore, animals aren't capable of morality. Yet trying to see "human" patterns of behavior in non-human animals stymies research and keeps us from really learning what animals themselves are like. We need as much as possible to suspend our assumptions about human morality when we study animals.

Often researchers are looking for "precursors" of morality in non-human species, or for what we might call evolutionary antecedents or "roots" or "proto-morality." These, presumably, are behaviors that by themselves don't constitute morality, but that fostered the development of morality in humans. For example, we might say that mice (Langford et al., 2006) and rats (Ben-Ami Bartal, Decety, \& Mason, 2011) have the capacity for empathy but really it is only a kind of pre-empathy or protoempathy. This begins to feel rather slippery because we must make some seemingly arbitrary judgment about when, along a spectrum of empathy behaviors, we switch from plain old animal empathy into full-blown moral (read: human) empathy. What is the magic je ne sais quoi that makes empathy a "moral" behavior? Can we really say that there is anything more to it than simply being possessed by a human, and not some "lower" animal? At what point does "proto-morality" become morality in primates or canids? Are justice behaviors in animals really only the rough precursors of real (human) justice? And if so, what exactly are they missing?

Generally this je ne sais quoi is thought to be the addition of rationality or reason, or the unique possession of a conscience. Human morality, it has long been assumed, is not simply instinctual reactions to environmental cues, but a deliberate and conscious thought process during which we decide how we ought to act in a given situation. Yet as we understand more about the neurobiology of moral behavior, we are coming to learn that morality is much less conscious and deliberate than has long been assumed. For example, the work of neuroscientists Antonio Damasio $(1994,2003)$ and Michael Gazzaniga (2005) has emphasized just how much morality is guided by chemical processes in the brain. Ethical impulses are "hardwired" behavioral predispositions that are poised to be invoked, or provoked, at any time, very often without our awareness. Other researchers, like Jonathan Haidt and Joshua Greene, are examining the role of emotion, and believe that the vast majority of moral behavior is guided by emotion and very little is subjected to conscious, rational deliberation (Greene \& Haidt, 2002; Haidt, 2007; see also Churchland, 2011). 
If we view human behavior through the lens of ethology-studying Homo sapiens as though it were a species of animal-we can similarly come to appreciate that the differences between humans and animals are a matter of degree, not kind. For example, distinguished ethologist Robert Hinde in his painstaking study of human moral behavior describes having a "good conscience" as working to maintain congruency between one's own actions and what he calls the "self-system"- the internalized moral norms of a given society (Hinde, 2002, p. 53). Non-human animals, too, internalize the behavioral norms of their society and engage in flexible self-monitoring of behavior and thus could be said to have conscience.

What often lurks behind the resistance to animal morality is a perceived threat to human uniqueness. Yet understanding that moral behaviors are broadly distributed evolutionary adaptations does not need to be threatening. Of course humans are unique! So too are other animals. Rather than threatening our uniqueness, research into animal morality will help us understand even more clearly what is different and special about human moral behavior. Human morality seems, based on what we know now, to be more highly developed, more complex and nuanced, than those systems found in other species. But we must also bear in mind that humans have been studying human morality for millennia and we take an intense interest in ourselves. We only started really looking at animal morality within the last decade and as we learn more we are likely going to be surprised at the cognitive and emotional subtlety present in animal behaviors. Although our uniqueness is not at stake, what is sometimes called our "exceptionalism" is. The philosophical stance that humans are "higher" or "better" or of greater intrinsic worth has no grounding in science.

\section{Ethical Implications of Social Justice Research: Upping the Ante}

When we wrote Wild Justice, we deliberately avoided discussing the ethical implications of our work because we wanted people to openly consider the scientific case for animal morality. We didn't want skeptical readers to think that we were using the science to push through an underlying moral agenda for animal protection or animal rights. But our evolving picture of who animals are will most certainly help enlighten our treatment of them. Any nuanced and careful consideration of ethics must, as a matter of course, be based on clear empirical, "objective" data. People use scientific information to think more carefully about ethics and for the most part science helps move us forward toward better, more considered moral judgments and public policies.

Unfortunately, animal ethics seems to lag behind science by at least 10-20 years. It was at least a full decade after almost all researchers finally agreed and openly admitted that animals do, in fact, feel pain and feel it in very much the same ways as humans that welfare standards began to seriously address animal pain. And even though the scientific case for animal emotions was well-established by the turn of the twenty-first century, welfare standards still do not adequately address psychological forms of suffering such as fear, loneliness, or boredom, nor do they take into account the social needs of animals. For example, rigorous scientific research has shown that mice feel empathy but nothing has been done to protect them from highly invasive research in the United States (Bekoff, 2010). As research into justice and other complex forms of sociality develops, our ethical standards are once again going to need to play catch up, and one of the important tasks will be to figure out what exactly the new information about animals means for animal protection.

The growing body of literature on justice in animals may have direct positive impact on animal welfare by upping the ante in the arena of moral justification. Moral justification for using animals, for holding them captive, isolating them and preventing social interactions, causing them to suffer, and killing them boils down to some weighing of their interests against our own. The interests of animals have "weighed" very little on the scales but every time we add richness and depth to our picture of animals their interests 
weigh a bit more. It is much easier to justify invasive research on a non-thinking, non-feeling entity (such as yeast, perhaps) than it is to justify inflicting suffering on a highly intelligent, emotional, and socially complex creature who, like us, forms friendships, feels joy and sorrow, and becomes indignant when treated unfairly.

We need to seek a balance: having a robust picture of the inner lives of animals most certainly furthers our efforts to protect and improve welfare conditions. At the same time, the more we know the stronger the ethical constraints on research (and the less we may be able to discover in the future). We reach a tipping point where we might ask ourselves "how much more do we really need to know?" For instance, we surely know enough about animal emotions so that invasive work is no longer justified (Bekoff, 2010). Where will the asymptote occur in research on moral behavior?

As much as possible, research should focus on wild populations. The capture of wild animals for captive studies should stop, as should the breeding of captive animals for the sole purpose of using them as research subjects. Still, some research on captive animals may be ethically permissible, and even beneficial for the animals themselves. For example, certain Great Ape populations are protected in sanctuaries and these can be valuable populations to study. They have the advantage of being situated in "semi-natural" environments where researchers are more likely to observe natural behaviors than in a laboratory, or with a very small captive group. Duke University researcher Brian Hare is doing fruitful studies on theory of mind on bonobos in the Lola Ya sanctuary in Democratic Republic of Congo (Hare, 2012). This research actually enhances the lives of the bonobos because it offers them daily social and mental stimulation.

Dogs are quickly becoming a favorite model of comparative psychologists. They provide a potential population for study, without many of the ethical drawbacks of using captive wild animals (Range et al., 2008; Miklosi, 2009; Hare et al., 2010). It is easy to recruit dog owners and the dogs themselves are usually willing and enthusiastic participants. Shelter dogs may provide another study population, and giving them interesting work would certainly enrich and improve their lives.

If research on captive animals is going to continue we need to do much better in our efforts to promote individual welfare and to prevent suffering. Basic needs go well beyond narrow, physiological requirements, and include mental health, social relationships, communicating with conspecifics, expressing normal sexual behaviors, and being able to nurture offspring. Work on animal preferences offers one concrete example of how we can learn to do better and illustrates how science can improve ethics. Preference testing, where an individual animal's preferences are measured and assessed, can help us refine methods used in animal research (for example, Dawkins, 2004). For example, mice learn to navigate a maze just as quickly when they are "rewarded" by being allowed into a dark hiding place as when they are "punished" with an electric shock (Hare, 2012, p. 12). Even noninvasive research can be made much more humane by paying attention to the mental and emotional needs of animals. For example, Hare points out that some social animals experience extreme fear when taken away from their companions, even for research that simply involves playing cognitive "games," illustrating that even research we, ourselves, might judge to be totally non-invasive and not at all harmful can in fact cause suffering.

\section{Looking Ahead}

These are very exciting times to be students of animal behavior. There still is so much to learn about other animals and research on social justice is perhaps one of the most important areas of inquiry. Coming to a fuller understanding of social justice in diverse animal species will require us to learn the 
details about what they do, how they live, how they negotiate social interactions, how they resolve conflicts and settle disputes, how they share finite resources fairly, and how we must treat them.

\section{NOTES}

1 The challenge of providing a narrower definition of justice is similar to that faced by researchers who have been interested in social play and dominance, both of which are important to studies of social justice. Over the course of about 30 years, as play was studied in diverse species, researchers came to better working definitions of this phenomenon, and these are continually being refined (see Bekoff \& Byers, 1981, 1998; Burghardt, 2005; Fagen, 1981). "Dominance" still eludes precise definition (for example, see Bernstein, 1981 and Bekoff, 2012 and extensive comments).

2 One reviewer offered this perspective: "The sense of justice employed must not be so broad that any behavioral regularity that engenders expectations in members of a social group - expectations that arouse indignation when the regularities are flouted - counts as justice. For example following [Robert] Solomon (and cited in Wild Justice), suppose wolves have, following a kill, a set of expectations concerning whom gets to eat when. This, I think would be too broad to count as justice. The danger is that it makes the case for justice in animals vacuous. Would anyone doubt that there are patterns of behavior in social mammals whose flouting can engender hostile feelings? If this is all justice is, then surely the question of whether animals can exhibit justice would have been answered in the affirmative a long time ago."

A second reviewer (Peter Corning) offered the following distinction between justice and fairness: "Justice would seem to refer to what an individual deserves, independently of others. Fairness, on the other hand, involves a judgment that is bound up with our relationships with others and very often has a distributive focus-how the benefits and costs are allocated in our social relationships. I define it as striking a balance or compromise between different, perhaps conflicting needs, interests and deserts." This reviewer also proposes that we identify three distinct categories of fairness: equality, equity, and reciprocity. In our view, this nuanced vocabulary is exceedingly important. But these distinctions have developed within the human realm over millennia of careful study and work. It is too early to know whether these same distinctions are relevant to the study of animal behavior.

\section{References}

Allen, C., \& Bekoff, M. (1997). Species of mind: The philosophy and biology of cognitive ethology. Cambridge, MA: MIT Press.

Ayala, F. (2010). The difference of being human: Morality. Proceedings of the National Academy of Sciences, 107(Suppl 2), 9015-9022.

Bekoff, Marc. (1995). Play signals as punctuation: The structure of social play in canids. Behaviour, 132, 419-429.

Bekoff, M. (1996). Cognitive ethology, vigilance, information gathering, and representation: Who might know what and why? Behavioural Processes, 35, 225-237.

Bekoff, M. (2006). The public lives of animals: A troubled scientist, pissy baboons, angry elephants, and happy hounds. Journal of Consciousness Studies, 13, 115-131.

Bekoff, M. (2007). The emotional lives of animals: A leading scientist explores animal joy, sorrow, and empathy, and why they matter. Novato, CA: New World Library.

Bekoff, M. (2010). The animal manifesto: Six reasons for expanding our compassion footprint. Novato, CA: New World Library.

Bekoff, M. (2012). Social dominance is not a myth. Psychology Today. http://www.psychologytoday. com/blog/animal-emotions/201202/social-dominance-is-not-myth-wolves-dogs-and-other-animals. 
Bekoff, M., \& Byers, J. A. (1981). A critical reanalysis of the ontogeny and phylogeny of mammalian social and locomotor play: An ethological hornet's nest. In K. Immelmann, G. Barlow, M. Main, \& L. Petrinovich (Eds.), Behavioral development: The Bielefeld interdisciplinary project (pp. 296-337). Cambridge: Cambridge University Press.

Bekoff, M., \& Byers, J. A. (Eds.). (1998). Animal play: Evolutionary, comparative and ecological perspectives. New York: Cambridge University Press

Bekoff, M., \& Pierce, J. (2009). Wild justice: The moral lives of animals. Chicago: University of Chicago Press.

Ben-Ami Bartal, I., Decety, J., \& Mason, P. (2011). Empathy and pro-social behavior in rats. Science, 334 , 1427-1430.

Bernstein, I. S. (1981). Dominance: The baby and the bathwater. Behavior and Brain Sciences, 4, 419429.

Bräuer, J., \& Hanus, D. (2012). Social Justice Research (forthcoming).

Brosnan, S. F. (2006). Nonhuman species' reactions to inequity and their implications for fairness. Social Justice Research, 19(2), 153-185.

Brosnan, S. F., \& de Waal, F. B. M. (2003). Monkeys reject equal pay. Nature, 425, 297-299.

Brosnan, S. F., Houser, D., Leimgruber, K., Xiao, E., Chen, T., \& de Waal, F. B. M. (2010a). Competing demands of prosociality and equity in monkeys. Evolution and Human Behavior, 31(4), 279-288.

Brosnan, S. F., Schiff, H., \& de Waal, F. B. M. (2004). Tolerance for inequity may increase with social closeness in chimpanzees. Proceedings of the Royal Society B, 1560, 253-258.

Brosnan, S. F., Talbot, C., Ahlgren, M., Lambeth, S., \& Shapiro, S. (2010). Mechanisms underlying responses to inequitable outcomes in chimpanzees, Pan troglodytes. Animal Behaviour. doi: 10.1016/j.anbehav.2010.02.019.

Burghardt, G. (2005). The genesis of animal play: Testing the limits. Cambridge, MA: Bradford Books.

Chen, J., \& Houser, D. (2012). Social Justice Research (forthcoming).

Christen, M., \& Glock, H. (2012). Social Justice Research (forthcoming).

Churchland, P. (2011). Braintrust. Princeton, NJ: Princeton University Press.

Corning, P. (2011). The fair society. Chicago: University of Chicago Press.

Damasio, A. (1994). Descartes' error: Emotion, reason, and the human brain. New York: Penguin.

Damasio, A. (2003). Looking for Spinoza: Joy, sorrow, and the feeling brain. New York: Harcourt.

Dawkins, R. (1976). The selfish gene. New York: Oxford University Press.

Dawkins, M. S. (2004). Using behaviour to assess animal welfare. Animal Welfare, 13, 51-57.

Fagen, R. (1981). Animal play behavior. New York: Oxford University Press.

Gazzaniga, M. (2005). The ethical brain. New York: Dana Press.

Greene, J., \& Haidt, J. (2002). How (and where) does moral judgment work? Trends in Cognitive Science, $6,517-523$.

Haidt, J. (2007). The new synthesis in moral psychology. Science, 316, 998-1002.

Hare, B. (2012, in preparation). A culture of compassion relies on a preference based approach to animal welfare. http://www.friendsofbonobos.org/research.htm.

Hare, B., Rosati, A., Kaminski, J., Brauer, J., Call, J., \& Tomasello, M. (2010). The domestication hypothesis for dogs' skills with human communication: A response to Udell et al. (2008) and Wynne et al. (2008). Animal Behaviour, 79, e1-e6.

Heinrich, B. (1999). Mind of the raven: Investigations and adventures with wolf-birds. New York: Cliff Street Books.

Hinde, R. A. (2002). Why good is good: The sources of morality. New York: Routledge.

Horowitz, A. (2012). Fair is fine, but more is better: Limits to inequity aversion in the domestic dog. Social Justice Research, 25(2). doi:10.1007/s11211-012-0158-7.

Jensen, K., Call, J., \& Tomasello, M. (2007). Chimpanzees are rational maximizers in an ultimatum game. Science, 318, 107-109. 
Langford, D. J., Crager, S. E., Shehzad, Z., Smith, S. B., Sotocinal, S. G., Levenstadt, J. S., et al. (2006). Social modulation of pain is evidence of empathy in mice. Science, 312, 1967-1970.

Lehner, P. N. (1996). Handbook of ethological methods (2nd ed.). New York: Cambridge University Press.

Miklosi, A. (2009). Dog behaviour, evolution, and cognition. Oxford: Oxford University Press.

Montgomery, S. (2011, November/December). Deep intellect. Orion. (http://www.orionmagazine.org/index.php/articles/article/6474/).

Neiworth, J. J., Johnson, E., Whillock, K., Greenberg, J., \& Brown, V. (2009). Is a sense of inequity an ancestral primate trait? Testing social inequity in cotton top tamarins (Saguinus oedipus). Journal of Comparative Psychology, 123(1), 10-17.

Olson, K. (2012). Social Justice Research (forthcoming).

Peterson, D. (2011). The moral lives of animals. Boston: Houghton-Mifflin.

Pierce, J., \& Bekoff, M. (2012). Wild justice redux: What we know about social justice in animals and why it matters. Social Justice Research, 25(2). doi:10.1007/s11211-012-0154-y.

Price, S. A., \& Brosnan, S. F. (2012). To each according to his need? Variability in the responses to inequity in non-human primates. Social Justice Research, 25(2). doi:10.1007/s11211-012-0153-z.

Raihani, N. J. \& McAuliffe, K. (2012). Does inequity aversion motivate punishment? Cleaner fish as a model system. Social Justice Research, 25(2). doi:10.1007/s11211-012-0157-8.

Range, F., Horn, L., Viranyi, Z., \& Huber, L. (2008). The absence of reward induces inequity aversion in dogs. Proceedings of the National Academy of Sciences. http://www.pnas.org/cgi/doi/10.1073/pnas.0810957105.

Range, F., Leitner, K., \& Virányi, Z. (2012). The influence of the relationship and motivation on inequity aversion in dogs. Social Justice Research, 25(2). doi:10.1007/s11211-012-0155-x.

Rawls, J. (1971). A theory of justice. Cambridge: Belknap Press of Harvard University Press.

Schaller, G. B., \& Lowther, G. R. (1969). The relevance of carnivore behavior to the study of early hominids. Southwestern Journal of Anthropology, 25, 307-341.

Skitka, L. (2012). Social Justice Research (forthcoming).

Sussman, R. W., \& Cloninger, C. R. (Eds.). (2011). Origins of altruism and cooperation. Dordrecht: Springer.

Sussman, R. W., Garber, P. A., \& Cheverud, J. M. (2005). Importance of cooperation and affiliation in the evolution of primate sociality. American Journal of Physical Anthropology, 128, 84-97.

Talbot, C. F., Freeman, H. D., Williams, L. E., \& Brosnan, S. F. (2011). Squirrel monkeys' response to inequitable outcomes indicates a behavioural convergence with the primates. Biology Letters, 7 , 680-682.

Thompson, P. R. (1975). A cross-species analysis of carnivore, primate, and hominid behaviour. Journal of Human Evolution, 4, 113-124.

Tinbergen, N. (1972). The spotted hyena in Hans Kruuk. Chicago: University of Chicago Press.

Tomasello, M., \& Call, J. (2011). Methodological challenges in the study of primate cognition. Science, 334, 1227-1228.

van Wolkenten, M., Brosnan, S. F., \& de Waal, F. B. M. (2007). Inequity responses of monkeys modified by effort. Proceedings of the National Academy of Sciences, 104(47), 18854-18859.

Yamamoto, S., \& Takimoto, A. (2012). Social Justice Research (forthcoming). 